Article

\title{
Investigation of Factors Influencing the Occurrence of 3C-Inclusions for the Thick Growth of on-Axis C-Face $4 \mathrm{H}-\mathrm{SiC}$ Epitaxial Layers
}

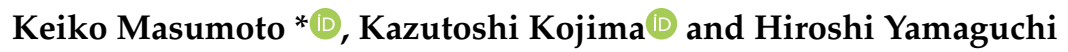 \\ National Institute of Advanced Industrial Science and Technology, Central 2 1-1-1 Umezono, \\ Tsukuba 305-8568, Japan; kazu-kojima@aist.go.jp (K.K.); hiroshi-yamaguchi@aist.go.jp (H.Y.) \\ * Correspondence: keiko-masumoto@aist.go.jp
}

Received: 9 October 2020; Accepted: 25 October 2020; Published: 28 October 2020

\begin{abstract}
In this study, we grew homoepitaxial layers on 3-inch on-axis carbon-face $4 \mathrm{H}$-silicon carbide substrates and attempted to suppress the generation of $3 \mathrm{C}$-inclusions. It was found that the $3 \mathrm{C}$-inclusion density decreased with increasing time spent on reaching an objective flow rate for the precursors. It is suggested that $3 \mathrm{C}-\mathrm{SiC}$ nucleation occurred on large terraces of the on-axis substrates, which existed before the substrates were covered with spiral hillocks. This nucleation was suppressed owing to the decrease in the degree of supersaturation at the initial growth stage. Moreover, we found that the 3C-inclusions were also generated owing to contamination in the form of graphite products. Furthermore, we succeeded in growing a thick on-axis $4 \mathrm{H}-\mathrm{SiC}$ homoepitaxial layer on a 3-inch substrate and demonstrating its free-standing epitaxial layer with a thickness of $182 \mu \mathrm{m}$ and a 3C-inclusion density of $2.0 \mathrm{~cm}^{-2}$.
\end{abstract}

Keywords: silicon carbide; epitaxial layer; on-axis; spiral growth; 3C-inclusions

\section{Introduction}

Currently, silicon ( $\mathrm{Si})$ power devices are widely used; however, further improvements in the consumption efficiency and applicability of power devices are required. Silicon carbide (SiC) power devices have low energy loss and can be used at higher temperatures. Furthermore, owing to their physical properties-including a wide bandgap and high thermal conductivity [1] - SiC device-systems can be miniaturized. There are many polytypes of $\mathrm{SiC}$, such as $4 \mathrm{H}, 6 \mathrm{H}$ and $3 \mathrm{C}$. $4 \mathrm{H}-\mathrm{SiC}$ is primarily used for power devices because of its higher electron mobility and wider bandgap [2,3]. Consequently, 4H-SiC power devices-such as Schottky barrier diodes and metal-oxide-semiconductor field-effect transistors (MOSFETs) with blocking voltages below a few kilovolts-are commercially used in air-conditioning equipment, train components, etc.

$4 \mathrm{H}-\mathrm{SiC}$ insulated-gate bipolar transistors (IGBTs), with blocking voltages above $10 \mathrm{kV}$, are expected to gain widespread use because they can reduce the size and losses in electronic components used in smart grids and high-voltage DC transmission systems [4,5]. In particular, obtaining n-channel SiC IGBTs is important because the effective mobility of the $\mathrm{n}$-channel SiC MOS structure is higher than that of its p-channel counterpart [6]. Furthermore, the carrier lifetime in a lightly-doped n-type $\mathrm{SiC}$ epitaxial layer is longer than that in its lightly-doped p-type counterpart $[7,8]$, which leads to the low on-resistance of $\mathrm{n}$-channel SiC IGBTs. To fabricate n-channel SiC IGBTs, a $\mathrm{p}^{+}$collector is required. Heavily acceptor-doped and low-resistivity $\mathrm{p}$-type substrates would be used as the $\mathrm{p}^{+}$collector to ensure the simplest and lowest-cost fabrication process if such p-type substrates could be obtained. Research on heavily Al-doped p-type $4 \mathrm{H}$-SiC bulk crystal growth faces some significant challenges, such as improving the growth rate and suppressing $6 \mathrm{H}-\mathrm{SiC}$ polytype inclusions [9]. Since low-resistivity 
and high-quality p-type bulk growth is still difficult, the structure of the n-channel SiC IGBT-including the $\mathrm{p}^{+}$collector and thick $\mathrm{n}^{-}$drift layer-can be ensured through epitaxial growth on a standard $\mathrm{n}$-type substrate that is removed by polishing after the epitaxial growth [5]. Thus, a free-standing epitaxial layer is necessary for producing n-channel IGBTs.

$4 \mathrm{H}-\mathrm{SiC}$ epitaxial growth has been achieved by using step-flow growth on $4^{\circ}$ off-angle substrates to enhance polytype stability [2,10]; however, two principle problems exist in the process of off-angle epitaxial growth, the first of which is basal plane dislocations (BPDs). It has been reported that the generation of single Shockley stacking faults, attributed to BPDs propagating from the off-angle substrates to the epitaxial layers, results in the degradation of bipolar device performance in the forward-voltage direction [11]. The BPDs in epitaxial layers must be removed to improve the yield of SiC IGBTs. The second problem involves the difficulty in thickening the epitaxial layers. It has been reported that high-density 3C-inclusions are easily generated at the wafer edge of the step-flow upstream side because the stacking information of the substrate cannot be applied at the wafer edge of the step-flow upstream side owing to the absence of steps; the generation area of the high-density 3C-inclusions increased with increases in epitaxial layer thickness [12]. The generation of these high-density 3C-inclusions at the wafer edge of the step-flow upstream side also should be suppressed to improve the yield of SiC IGBTs.

Spiral growth on on-axis $\mathrm{SiC}$ substrates resolves these problems. Firstly, in the on-axis substrates, BPDs do not propagate to the epitaxial layers because the growth direction is perpendicular to the basal plane. Furthermore, it has been reported that the generation of single Shockley stacking faults is not observed for PiN diodes fabricated using on-axis SiC epitaxial wafers [13]. Secondly, the generation of high-density $3 \mathrm{C}$-inclusions at the wafer edge of the step-flow upstream side can be suppressed by using spiral growth because this type of growth originates from threading screw dislocations (TSDs), which eternally supply steps even though the thickness of the epitaxial layers increases. On-axis SiC substrates have small off-angles, and spiral growth occurred when the off-angle was less than $0.05^{\circ}$ in our previous report [14]. Another group of researchers reported that spiral growth became the dominant mechanism when the off-angle was less than $0.15^{\circ}$, and both step-flow growth and spiral growth simultaneously took place when the off-angle was $0.15-0.5^{\circ}$ [15-17]. Thus, it is clear that spiral growth tends to occur at lower off-angles, but the reason for the boundary off-angle where the spiral growth occurs is unknown. We previously investigated the conditions surrounding spiral growth and found that this type of growth occurred when the off-angle was less than the tilt angles of spiral hillocks, because the growth rate of spiral growth became higher than that of step-flow growth [14]. Consequently, we have succeeded in growing on-axis $4 \mathrm{H}-\mathrm{SiC}$ homoepitaxial layers on the 3-inch substrates using spiral growth [14]. The next step to obtain high-yield n-channel SiC-IGBTs is the growth of thick, high-quality on-axis $4 \mathrm{H}-\mathrm{SiC}$ epitaxial layers using spiral growth.

The main problem when using on-axis $4 \mathrm{H}-\mathrm{SiC}$ substrates is suppressing the $3 \mathrm{C}$-inclusions, which will more likely be generated during on-axis epitaxial growth in comparison to $4^{\circ}$ off-angle growth $[14,16]$, although the presence of high-density 3C-inclusions attributed to the absence of steps at the wafer edge of the step-flow upstream side can be suppressed. It is known that two-dimensional nucleation tends to occur when large terraces exist [2], and the polytype of the nucleus is 3C-SiC, which is stable at chemical vapor deposition (CVD) growth temperatures of $1500-1700{ }^{\circ} \mathrm{C}[2,18]$. On-axis $4 \mathrm{H}-\mathrm{SiC}$ substrates have much larger terraces than $4^{\circ}$ off-angle substrates, which leads to increased 3C-SiC nucleation. It is thought that the removal of generated 3C-SiC nucleation and the suppression of $3 \mathrm{C}-\mathrm{SiC}$ nucleation itself are effective in mitigating the creation of 3C-inclusions. From this perspective, the addition of chlorine gas is a good method to remove generated 3C-SiC nucleation because it has been reported that higher chlorine content in gas mixtures preferentially etches 3C-inclusions [16]. To suppress 3C-SiC nucleation itself, the degree of supersaturation must be reduced. This means that increases in growth rate are difficult to establish because 3C-SiC nucleation occurs more easily at high growth rates, owing to higher degrees of supersaturation. It has been reported that on-axis silicon-face (Si-face) epitaxial growth rates are limited to below $10 \mu \mathrm{m} / \mathrm{h}$ to 
suppress the 3C-inclusions, irrespective of the addition of $\mathrm{HCl}$, in both the spiral and step-flow growth modes [19]. However, the growth rate should be increased to grow thick epitaxial layers. In contrast, the growth rate of $2 \times 2 \mathrm{~cm}^{2}$ on-axis Si-face epitaxial layers was increased to $100 \mu \mathrm{m} / \mathrm{h}$ by using a particular chlorinated precursor-methyltrichlorosilane (MTS) - but this high growth rate could be obtained only in the upstream area of the reaction chamber because of an abrupt depletion effect that was attributed to MTS [20]. It is thought that MTS is not suitable for large diameter growths. Therefore, we focused on on-axis $4 \mathrm{H}-\mathrm{SiC}$ carbon-face (C-face) epitaxial growth for increasing the growth rate. It has been reported that step bunching seldom occurs in C-face epitaxial growth in comparison to the Si-face in step-flow growth because the surface energy of the C-face is smaller than that of the Si-face [2,21]. This means that the steps on the spiral hillocks of the C-face on-axis $4 \mathrm{H}-\mathrm{SiC}$ epitaxial layer also have fewer occurrences of bunching in comparison to the Si-face. It has been reported that the step height near the top of the spiral hillocks at the C-face was $0.5 \mathrm{~nm}$ corresponding to a half-unit cell [14], and those at the Si-face was $1 \mathrm{~nm}$ corresponding to a one-unit cell [20]. Therefore, the terrace widths of the spiral hillocks on the C-face must be narrower than those of the Si-face during on-axis epitaxial growth. We expected that the on-axis C-face growth rate would increase concurrently with the suppression of 3C-inclusions.

We also focused on a process for fabricating a free-standing epitaxial layer, which is usually conducted by polishing substrates, as described above [5]. This process wastes the substrate material, increasing the cost of SiC-IGBTs. A SiC ingot slicing method, referred to as the KABRA process-where substrates are peeled off using a separation layer formed by an irradiating laser from the upper surface of the ingot-has been developed by the DISCO Corporation [22,23]. We applied this process to fabricating the free-standing epitaxial layer because the substrate that separates from the epitaxial layer can be reused.

In this study, we first attempted to suppress the generation of 3C-inclusions in the $4 \mathrm{H}$-SiC C-face on-axis epitaxial layers by optimizing growth conditions; this was done to investigate the source of the $3 \mathrm{C}$-inclusions. Next, the thick on-axis $4 \mathrm{H}-\mathrm{SiC}$ epitaxial layer was grown, and the thick free-standing epitaxial layer was demonstrated by separating it from the substrate using the KABRA process.

\section{Experimental Procedure}

Homoepitaxial layers were grown on commercially available 3 -inch C-face $4 \mathrm{H}$-SiC substrates (SICC and Sicrystal) with surface orientations close to perfectly on-axis (less than $0.05^{\circ}$ off-angle). A vertically blown CVD system, where substrates were oriented perpendicular to the gas flow, was used for this purpose [24]. $\mathrm{H}_{2}(9 \mathrm{~N})$ was used as the carrier gas, $\mathrm{SiH}_{4}(5 \mathrm{~N})$ and $\mathrm{C}_{3} \mathrm{H}_{8}(5 \mathrm{~N})$ were used as the precursors, $\mathrm{N}_{2}$ was used as the doping gas and $\mathrm{HCl}(5 \mathrm{~N})$ was used as the additive gas. The epitaxial growth was carried out at $1580-1590{ }^{\circ} \mathrm{C}$ and $2.7 \mathrm{kPa}$. The growth rate was either approximately 20 or $40 \mu \mathrm{m} / \mathrm{h}$. The $\mathrm{H}_{2}$ flow rate was $30 \mathrm{slm}$. The $\mathrm{SiH}_{4}$ and $\mathrm{C}_{3} \mathrm{H}_{8}$ flow rates were 27 and $10.6 \mathrm{sccm}$, respectively, at the growth rate of $20 \mu \mathrm{m} / \mathrm{h}$, and 54.1 and $21.2 \mathrm{sccm}$, respectively, at the growth rate of $40 \mu \mathrm{m} / \mathrm{h}$. The $\mathrm{C} / \mathrm{Si}$ ratio was maintained at 1.2. The $\mathrm{N}_{2}$ flow rate was $2 \mathrm{sccm}$, and the $\mathrm{HCl}$ flow rate varied between 0 and $810 \mathrm{sccm}$. We also varied the time spent on reaching the objective flow rate of the precursors (ramp-up time) from 5 to $90 \mathrm{~min}$. Figure 1 shows a growth-process diagram explaining the ramp-up time. The flow rate of $\mathrm{C}_{3} \mathrm{H}_{8}$ increased from the lower control limit of the mass flow controller to the objective value, and that of $\mathrm{SiH}_{4}$ was controlled to maintain a fixed C/Si ratio. The carrier concentration of the n-type epitaxial layer, obtained through capacitance-voltage measurements, was approximately $3-7 \times 10^{15} \mathrm{~cm}^{-3}$.

Surface observation of the on-axis $4 \mathrm{H}-\mathrm{SiC}$ epitaxial layers was carried out using Nomarski optical microscopy (NOM; OLYMPUS BX51, Tokyo, Japan) and tapping-mode atomic force microscopy (AFM; Veeco Nanoscope, Plainview, NY, USA). The 3C-inclusion density was determined through photoluminescence (PL) images obtained using 295-370 $\mathrm{nm}$ bandpass $\mathrm{Hg}$ lamp excitation, whose power density was $4500 \mathrm{mWcm}^{-2}$, and detected using a $750 \mathrm{~nm}$ long-pass filter at room temperature (PHOTON Design SemiScope, Tokyo, Japan). We confirmed that the 3C-inclusions exhibited dark contrasts in 
these PL conditions, as described in Ref. [25] by PL spectroscopy with the same setting used in our previous report [14]. PL images of wafer size were made by merging images, which were obtained by using microscope objective lens with magnification of $5 \times$. The origin of the $3 C$-inclusion was observed using cross-sectional scanning electron microscopy (SEM; Carl Zeiss Merlin, Oberkochen, Germany), transmission electron microscopy (TEM; HITACHI H9000 UHR, Tokyo, Japan) and energy-dispersive X-ray spectroscopy (EDX; JEOL JED-2300, Tokyo, Japan).

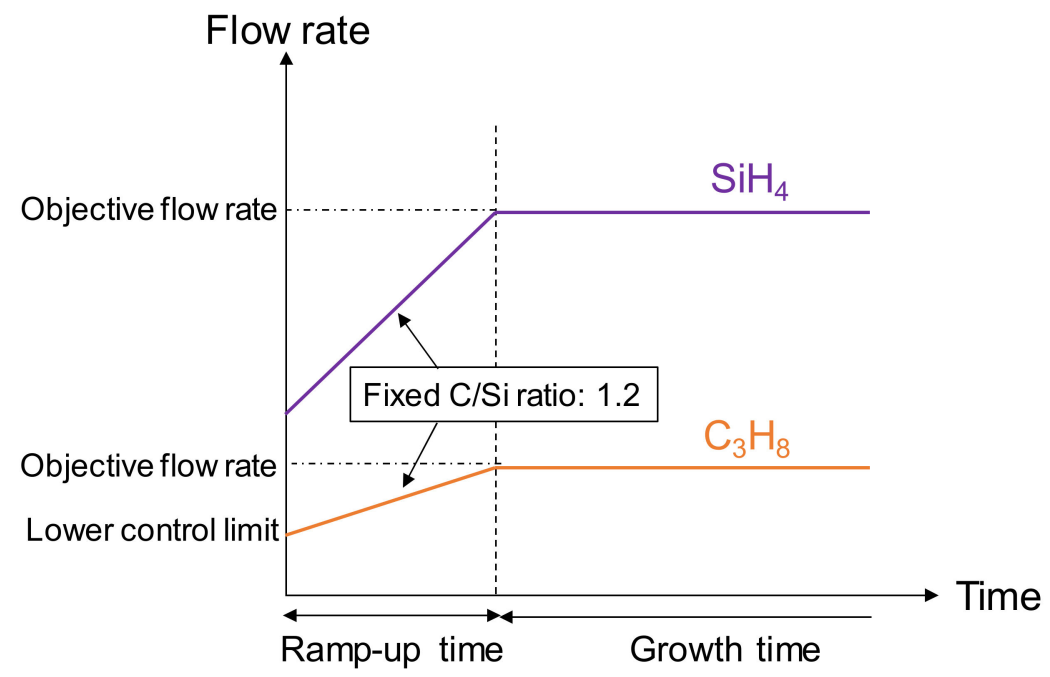

Figure 1. Growth process diagram of on-axis $4 \mathrm{H}-\mathrm{SiC}$ epitaxial layers showing ramp-up time of the precursors flow rates.

\section{Results and Discussion}

\subsection{Effects of $\mathrm{HCl}$ Addition on 3C-Inclusions}

We first investigated the effect of $\mathrm{HCl}$ addition on the 3C-inclusion density because it has been reported that higher chlorine content in gas mixtures preferentially etches 3C-inclusions. The 3C-inclusion density gradually decreased with increases in the $\mathrm{Cl} / \mathrm{Si}$ ratio, from 0 to 10 , where a horizontal hot-wall CVD system was used [16]. We varied the $\mathrm{HCl}$ flow rate from 0 to $810 \mathrm{sccm}$ at a $\mathrm{SiH}_{4}$ flow rate of $27 \mathrm{sccm}$; the $\mathrm{Cl} / \mathrm{Si}$ ratio was varied from 0 to 30 . The growth rate and time were $20 \mu \mathrm{m} / \mathrm{h}$ and $1 \mathrm{~h}$, respectively. Figure 2a,b show NOM images of the on-axis $4 \mathrm{H}-\mathrm{SiC}$ epitaxial layer surface grown without and with $\mathrm{HCl}$ addition, respectively. The $\mathrm{HCl}$ flow rate in Figure $2 \mathrm{~b}$ was $540 \mathrm{sccm}$. These epitaxial layer surfaces are covered with spiral hillocks, and we confirmed that the epitaxial layers experienced spiral growth throughout the wafer, irrespective of the $\mathrm{HCl}$ flow rate.
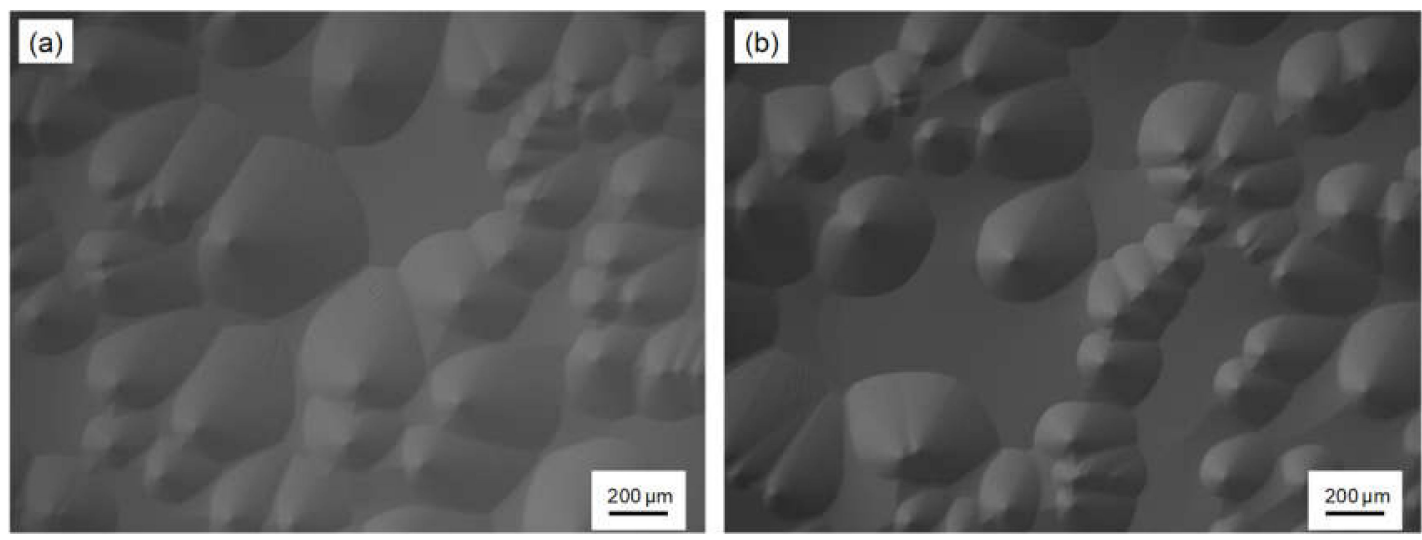

Figure 2. Nomarski optical microscopy (NOM) images of the on-axis $4 \mathrm{H}-\mathrm{SiC}$ epitaxial layer surface grown (a) without and (b) with $\mathrm{HCl}$ addition. (b): The $\mathrm{HCl}$ flow rate was $540 \mathrm{sccm}$. 
Figure $3 \mathrm{a}, \mathrm{b}$ show PL images of the $4 \mathrm{H}-\mathrm{SiC}$ homoepitaxial layers grown on the 3-inch substrates without and with $\mathrm{HCl}$ flow, respectively. The $\mathrm{HCl}$ flow rate in Figure $3 \mathrm{~b}$ was $810 \mathrm{sccm}$. It is known that 3C-inclusions in 4H-SiC epitaxial layers exhibit dark contrasts in these PL conditions [25], as indicated by the yellow arrows. The dark ellipses encircled by white dashed lines are the facet areas of the substrates. The 3C-inclusion density was calculated in concentric 2-inch areas of the 3-inch wafers-shown in the red dashed circles-because high-density 3C-inclusions were occasionally generated from the wafer edge. The occasional high-density 3C-inclusions at the wafer edge were not due to the absence of steps at the wafer edge of the step-flow upstream side because they were generated at various positions of the wafer edge, as shown in Figure 3. Figure $4 a, b$ show the dependence of the growth rate and the $3 \mathrm{C}$-inclusion density, respectively, on the $\mathrm{Cl} / \mathrm{Si}$ ratio. We found that the growth rate decreases with increase in the $\mathrm{Cl} / \mathrm{Si}$ ratio, especially when the $\mathrm{Cl} / \mathrm{Si}$ ratio is over 10 ; furthermore, the $3 \mathrm{C}$-inclusion density is approximately $1 \mathrm{~cm}^{-2}$, irrespective of the $\mathrm{HCl}$ flow rate. This indicates that the preferential etching of 3C-SiC by chlorine, reported in Ref. [17], did not occur, and the addition of $\mathrm{HCl}$ had no effect on the 3C-inclusion density in this experiment. We predicted that the etching selectivity between $3 \mathrm{C}-\mathrm{SiC}$ and $4 \mathrm{H}-\mathrm{SiC}$ was reduced when the etching rate for $4 \mathrm{H}-\mathrm{SiC}$ was high. Using this vertically blown CVD system, the etching rate for $4 \mathrm{H}-\mathrm{SiC}$ epitaxial layers was approximately $5 \mu \mathrm{m} / \mathrm{h}$ at $1590{ }^{\circ} \mathrm{C}$ in $\mathrm{H}_{2}$ atmosphere. The etching rate was much higher than that when using traditional horizontal hot-wall CVD systems. For example, it has been reported that the etching rate of a horizontal hot-wall CVD system is about $0.4 \mu \mathrm{m} / \mathrm{h}$ at $1660{ }^{\circ} \mathrm{C}$ in a $\mathrm{H}_{2}$ atmosphere [26]. Moreover, the growth rate decreases with the increase in the $\mathrm{HCl}$ flow rates, as shown in Figure 4a. This makes it clear that more effective etching phenomena took place during epitaxial growth when using this vertically blown CVD system, in comparison to horizontal hot-wall CVD systems. Owing to the high etching rate for $4 \mathrm{H}-\mathrm{SiC}$, no effect of preferential etching for 3C-SiC by $\mathrm{HCl}$ was observed. It should be noted that $\mathrm{SiC}$ deposition on the chamber walls was reduced by the addition of $\mathrm{HCl}$, leading to lower maintenance frequency. To maintain the growth rate, we used a $\mathrm{Cl} / \mathrm{Si}$ ratio below 10 for subsequent growth experiments.
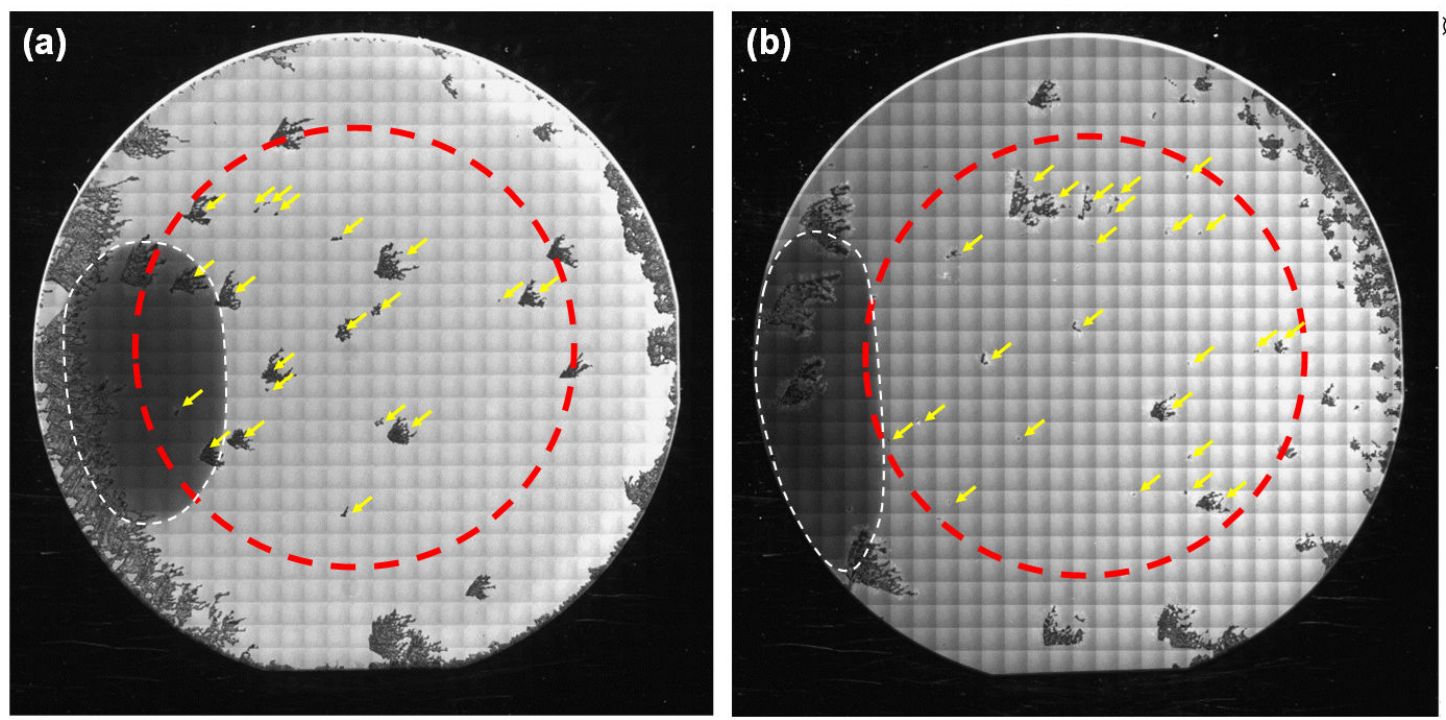

Figure 3. Photoluminescence (PL) images of the on-axis $4 \mathrm{H}-\mathrm{SiC}$ homoepitaxial layers grown on the 3-inch substrates (a) without and (b) with $\mathrm{HCl}$ flow. (b) The $\mathrm{HCl}$ flow rate was $810 \mathrm{sccm}$. 

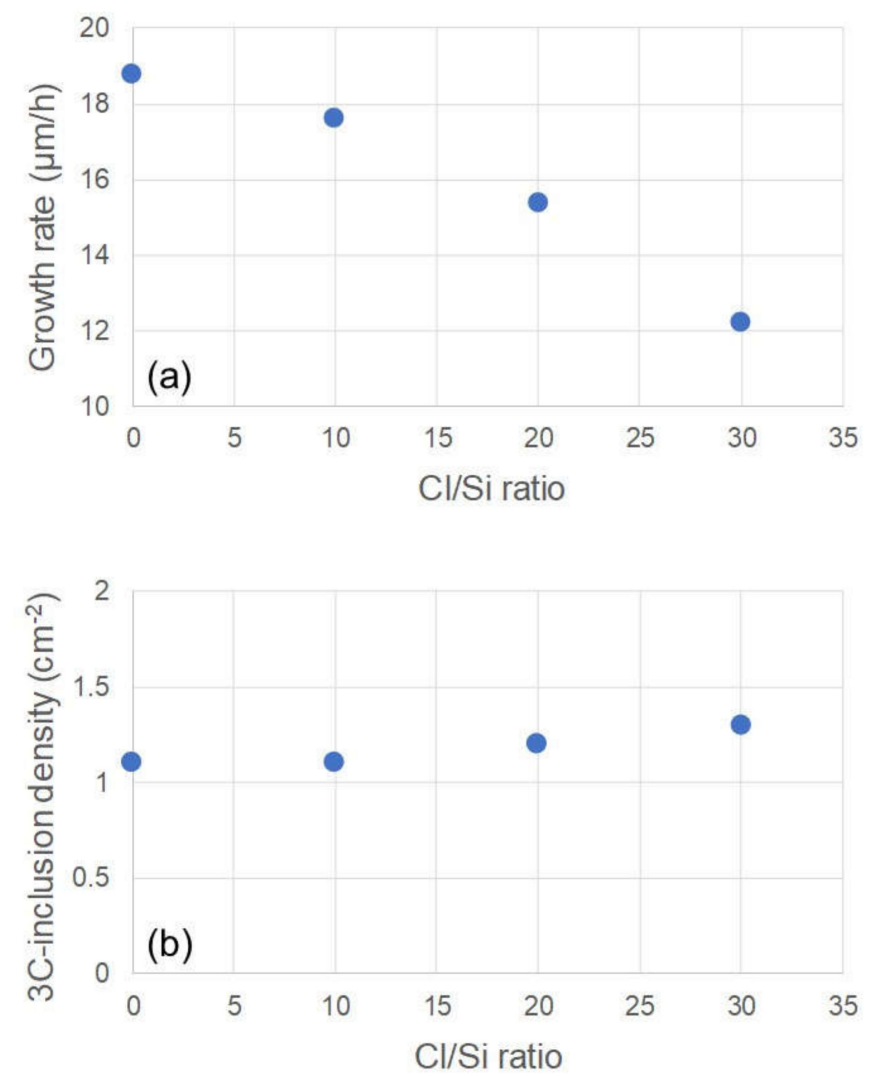

Figure 4. Dependence of (a) the growth rate and (b) the 3C-inclusion density of the on-axis $4 \mathrm{H}-\mathrm{SiC}$ epitaxial layers on the $\mathrm{Cl} / \mathrm{Si}$ ratio.

\subsection{Effects of Increasing the Ramp-Up Time on 3C-Inclusions}

It can be seen from the above results that it was difficult to suppress the 3C-inclusions using preferential etching for $3 \mathrm{C}-\mathrm{SiC}$ in this experiment. Therefore, the suppression of $3 \mathrm{C}-\mathrm{SiC}$ nucleation was necessary to decrease the $3 \mathrm{C}$-inclusion density. Our previous research showed that spiral growth occurred when the off-angle was less than the tilt angles of the spiral hillocks [14]. This means that the terraces of the on-axis substrates were larger than those of the spiral hillocks. It is thought that 3C-SiC nucleation occurs more easily on terraces of the substrate surface in comparison to terraces of the spiral hillocks. To suppress 3C-SiC nucleation on the substrate surface, the degree of supersaturation before the substrate is covered with spiral hillocks should be decreased. To accomplish this, we increased the ramp-up time at the initial growth stage and investigated its effect on the $3 \mathrm{C}$-inclusion density. We first grew an on-axis $4 \mathrm{H}-\mathrm{SiC}$ epitaxial layer at a growth rate and ramp-up time of $40 \mu \mathrm{m} / \mathrm{h}$ and $5 \mathrm{~min}$, respectively. The growth time was $30 \mathrm{~min}$. The growth rate was double that of the experiment using $\mathrm{HCl}$ addition, described in the previous section, toward achieving the goal of thick growth. Figure $5 \mathrm{a}, \mathrm{b}$ show a PL image of the $4 \mathrm{H}-\mathrm{SiC}$ homoepitaxial layer on the 3-inch substrate and an NOM image at the central region, respectively. The $3 \mathrm{C}$-inclusions are generated with a high density and with very rough morphology; in Figure 5a, they present a bright contrast owing to the scattering of the excitation light. Figure $5 \mathrm{~b}$ shows that the epitaxial layer is composed of $4 \mathrm{H}-\mathrm{SiC}$ spiral hillocks and high-density $3 \mathrm{C}$-inclusions with black contrast. We found that the 3C-inclusion density increased with an increase in growth rate. It is thought that the degree of supersaturation at the initial growth stage was too high to suppress $3 \mathrm{C}-\mathrm{SiC}$ nucleation on the on-axis substrates. 

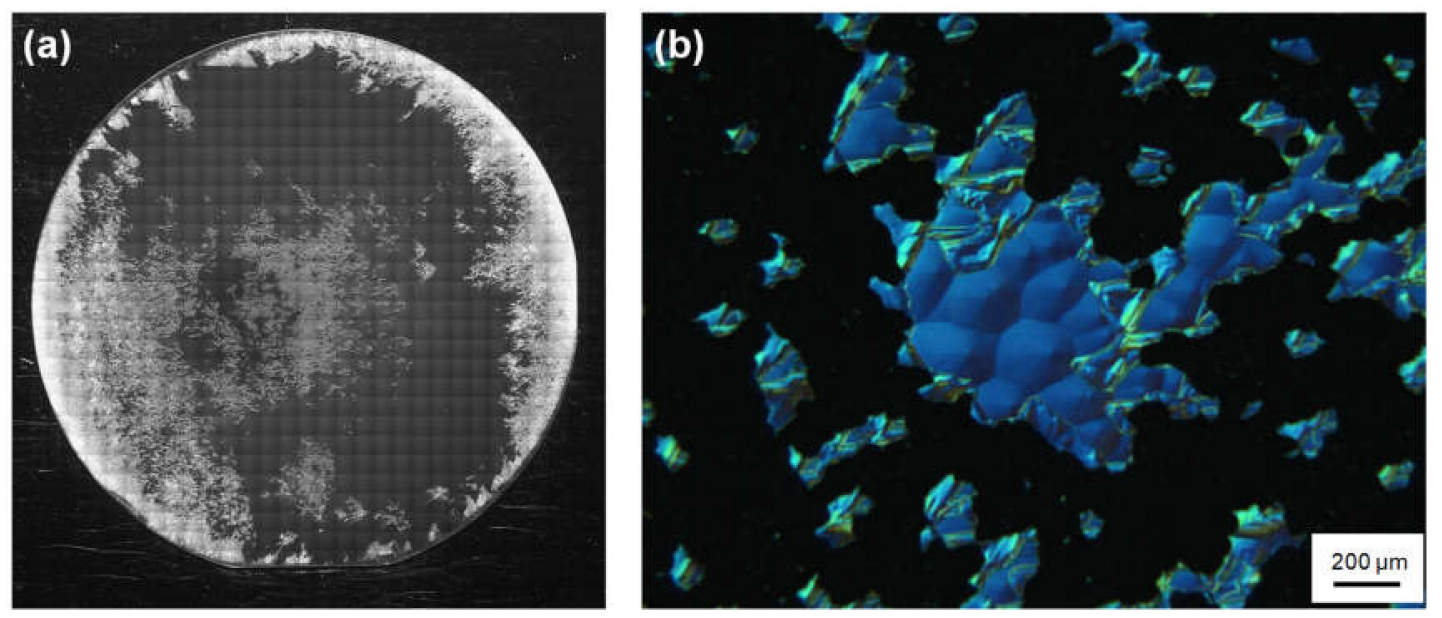

Figure 5. (a) PL image of the on-axis $4 \mathrm{H}-\mathrm{SiC}$ homoepitaxial layer grown on the 3 -inch substrate at the growth rate and ramp-up time of $40 \mu \mathrm{m} / \mathrm{h}$ and $5 \mathrm{~min}$, respectively, and (b) NOM image at the central region.

Then, to investigate the effects of decreases in the degree of supersaturation at the initial growth stage on the 3C-inclusion density, we varied the ramp-up time between 30 and $90 \mathrm{~min}$. Figure 6 shows an NOM image of the $4 \mathrm{H}-\mathrm{SiC}$ epitaxial layer surface grown with a ramp-up time of $60 \mathrm{~min}$. The $4 \mathrm{H}-\mathrm{SiC}$ epitaxial layer surface is covered with spiral hillocks, and we confirmed that the epitaxial layers experienced spiral growth throughout the wafer irrespective of the ramp-up time. Figure 7 shows the dependence of the 3C-inclusion density on the ramp-up time. The 3C-inclusion density was calculated in concentric 2 -inch areas of the 3 -inch wafer, as was the case in Figure $4 \mathrm{~b}$. The 3C-inclusion density drastically decreases with increases in ramp-up time, and saturates when the ramp-up time is over $60 \mathrm{~min}$. Figure 8 shows a PL image of the $4 \mathrm{H}-\mathrm{SiC}$ epitaxial layer grown at the ramp-up time of $60 \mathrm{~min}$. The 3C-inclusions are indicated using yellow arrows and the facet area of the substrate is encircled using a white dashed line. The 3 C-inclusion density was $0.2 \mathrm{~cm}^{-2}$ at a ramp-up time of $60 \mathrm{~min}$. This suggests that $3 \mathrm{C}-\mathrm{SiC}$ nucleation on the terraces of the substrates was suppressed by decreasing in the degree of supersaturation at the initial growth stage. As is the case in Figure 3, high-density 3C-inclusions-which are not caused by the absence of steps at the wafer edge of the step-flow upstream side-are generated at various positions of the wafer edge. The cause of the high-density $3 \mathrm{C}$-inclusions at the wafer edge is discussed in the following section.

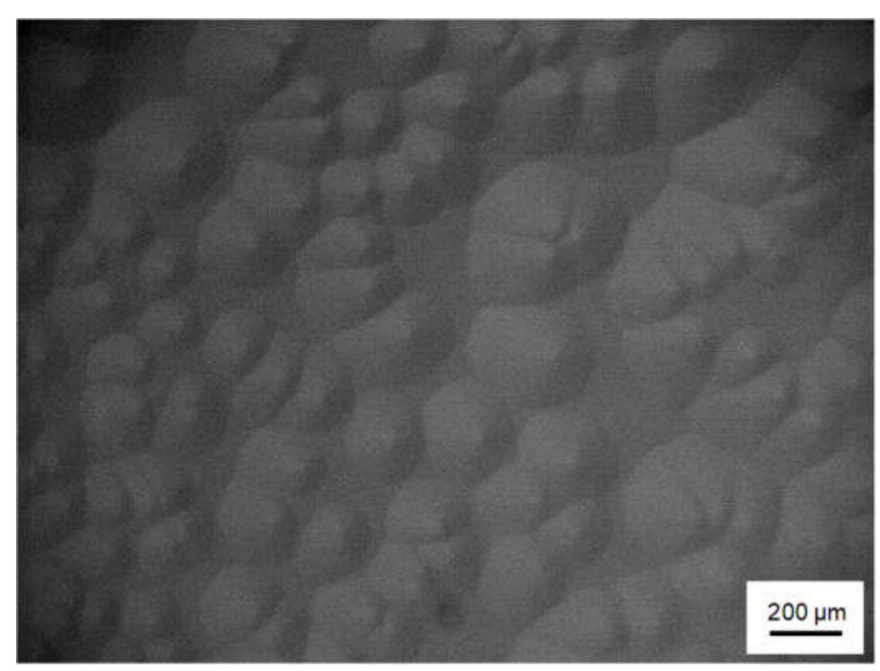

Figure 6. NOM images of the on-axis $4 \mathrm{H}-\mathrm{SiC}$ epitaxial layer surface at the growth rate and ramp-up time of $40 \mu \mathrm{m} / \mathrm{h}$ and $60 \mathrm{~min}$, respectively. 


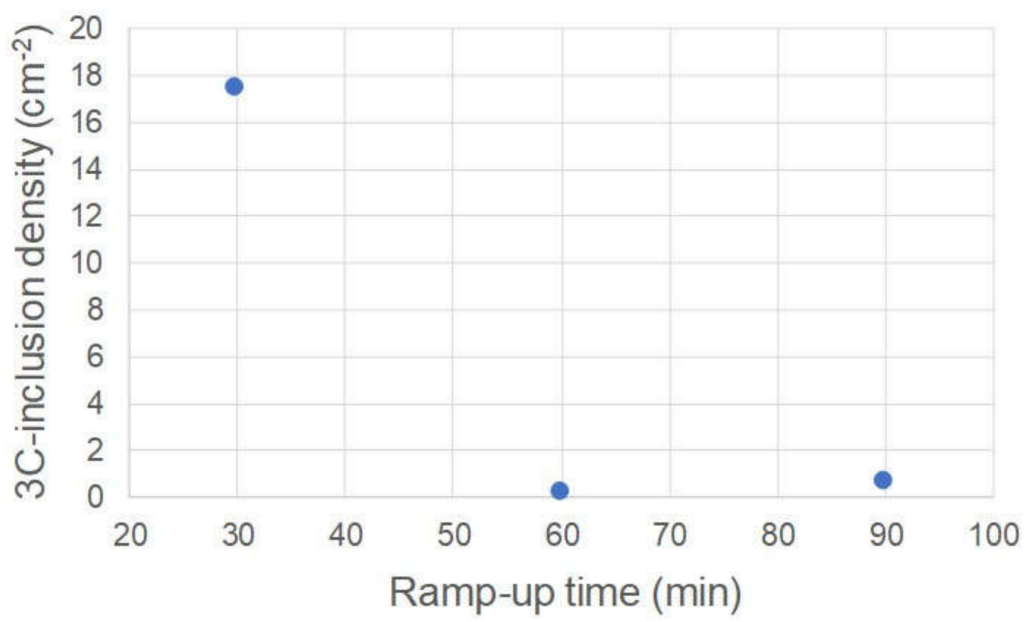

Figure 7. Dependence of the 3C-inclusion density of the on-axis $4 \mathrm{H}-\mathrm{SiC}$ epitaxial layers at the growth rate of $40 \mu \mathrm{m} / \mathrm{h}$ on the ramp-up time.

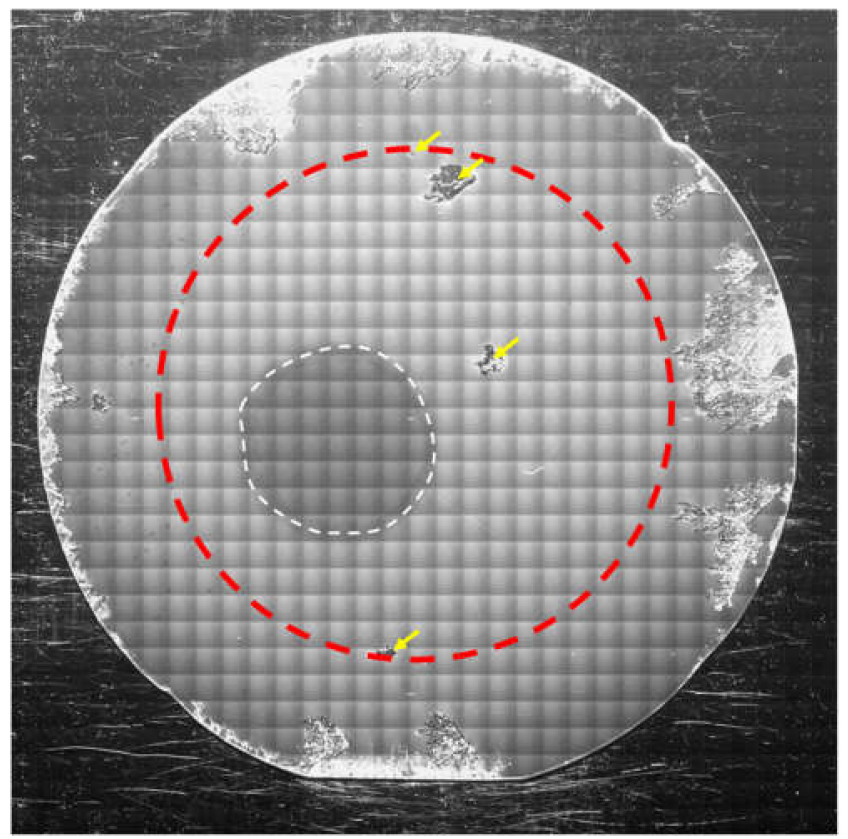

Figure 8. PL image of the on-axis $4 \mathrm{H}-\mathrm{SiC}$ homoepitaxial layer grown on the 3 -inch substrate at the growth rate and ramp-up time of $40 \mu \mathrm{m} / \mathrm{h}$ and $60 \mathrm{~min}$, respectively.

\subsection{Cause of the 3C-Inclusions}

As described above, the $3 \mathrm{C}-\mathrm{SiC}$ nucleation on the large terraces of the substrate surface was the cause of the $3 \mathrm{C}$-inclusions. However, it is thought that other causes for the $3 \mathrm{C}$-inclusions exist because the 3C-inclusion density became saturated at ramp-up times over $60 \mathrm{~min}$ and high-density $3 \mathrm{C}$-inclusions were generated at various positions of the wafer edge. To investigate the causes of the 3C-inclusions other than the high degree of supersaturation, we observed the origination of a 3C-inclusion in an epitaxial layer grown with a ramp-up time of $60 \mathrm{~min}$ using cross-sectional SEM, TEM and EDX. Figure 9a,b present cross-sectional SEM and bright-field TEM images, respectively, around the origination of a $3 \mathrm{C}$-inclusion. The yellow dashed lines indicate the interface between the epitaxial layer and the substrate, which was determined from the SEM contrast in Figure 9a. The interface between the 3C-inclusion and the $4 \mathrm{H}-\mathrm{SiC}$ epitaxial layer is indicated by the green dashed line in Figure 9b. We found that the 3C-inclusion was generated in the epitaxial layer a few hundred nanometers from the interface between the epitaxial layer and the substrate, and hollows-indicated 
using red arrows-exist near the origination of the 3C-inclusion. This indicates that the cause of the 3C-inclusion was contamination by foreign materials. To predict the source of these foreign materials, we performed elemental analysis using EDX, where Si, C and Ta were detected. We assumed that contamination occurred owing to Si depositing on graphite products in the chamber, in addition to contamination due to graphite products without and with TaC-coatings-as sources for $\mathrm{C}$ and $\mathrm{Ta}$, respectively. Figure 10a-c show EDX maps of $\mathrm{Si}, \mathrm{C}$ and $\mathrm{Ta}$, respectively, within the same area as that shown in Figure 9. The color intensity is strong at high-concentration areas of each element in these EDX maps. Figure 10a,c indicate that there was no high-concentration area of Si and Ta around the hollows. In contrast, Figure $10 \mathrm{~b}$ shows that the concentration of $C$ increased around the hollows. From these observations, it could be inferred that the graphite contamination occurred, owing to the graphite products without coatings. This contamination triggered the heterogeneous nucleation of 3C-SiC. As shown in Figures 3 and 8, high-density 3C-inclusions were occasionally generated at the wafer edge. It is thought that the cause of the high-density $3 \mathrm{C}$ inclusions at the wafer edge was contamination owing to graphite, because-during epitaxial growth-the $4 \mathrm{H}-\mathrm{SiC}$ substrates were placed on a graphite product without a coating. We inferred that the graphite contamination had a significant impact on the wafer edge. Thus, we found that the causes for the 3C-inclusions were the $3 \mathrm{C}-\mathrm{SiC}$ nucleation on the large terraces of the on-axis substrates and graphite contamination. This type of contamination can be reduced by coating graphite products with $\mathrm{SiC}, \mathrm{TaC}$, or other materials to further decrease the $3 \mathrm{C}$-inclusion density.
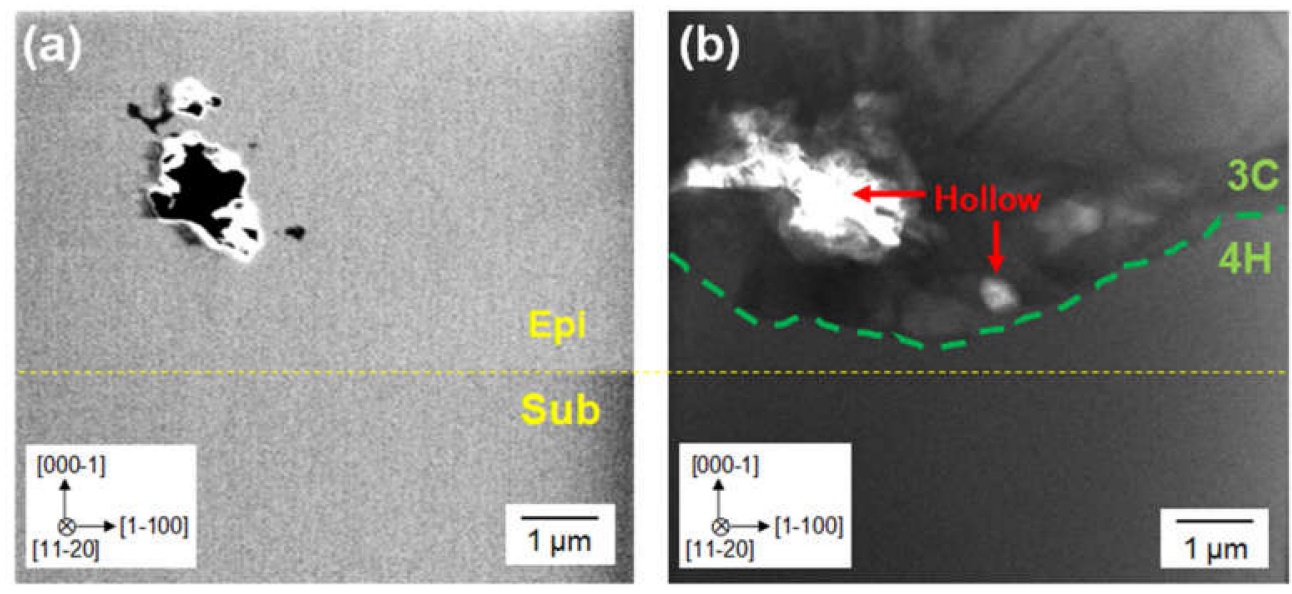

Figure 9. Cross-sectional (a) SEM and (b) bright-field TEM images around the origination of the $3 \mathrm{C}$-inclusion in the on-axis $4 \mathrm{H}-\mathrm{SiC}$ epitaxial layer at the growth rate and ramp-up time of $40 \mu \mathrm{m} / \mathrm{h}$ and $60 \mathrm{~min}$.
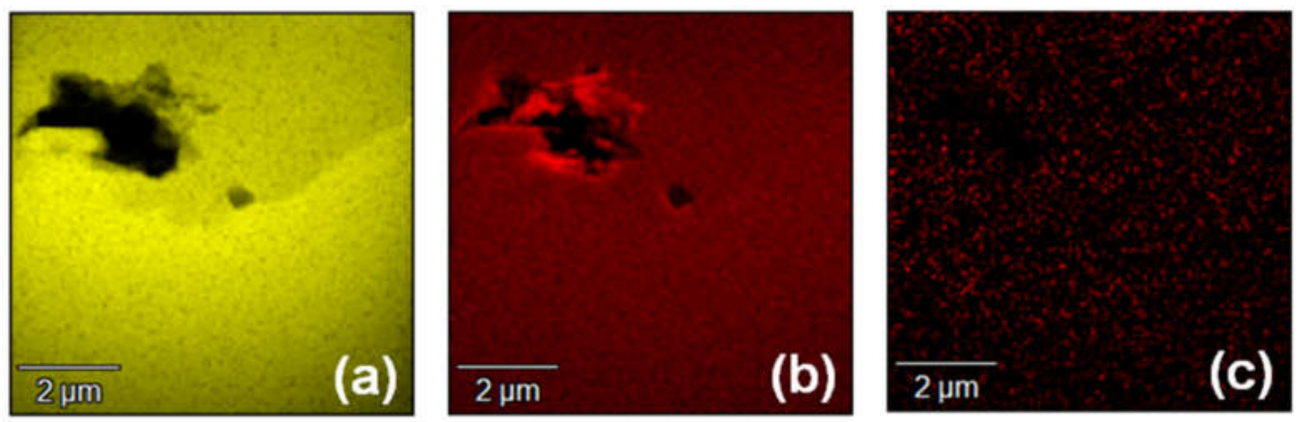

Figure 10. Energy-dispersive X-ray spectroscopy (EDX) maps of (a) $\mathrm{Si},(\mathbf{b}) \mathrm{C}$, and (c) Ta in the same area as that in Figure 9. 


\subsection{Growth of the 3-Inch Thick Epitaxial Layer and Free-Standing Demonstration}

Applying a ramp-up time of $60 \mathrm{~min}$, where 3C-SiC nucleation on the terraces of the substrates was suppressed, we grew a thick $4 \mathrm{H}-\mathrm{SiC}$ epitaxial layer at a growth rate of $40 \mu \mathrm{m} / \mathrm{h}$ for $5 \mathrm{~h}$. The thickness of the epitaxial layer was $194 \mu \mathrm{m}$. The 3C-inclusion density, calculated ignoring 3C-inclusions generated from the wafer edge, was $2.0 \mathrm{~cm}^{-2}$. This value is larger than $0.2 \mathrm{~cm}^{-2}$, which is the $3 C$-inclusion density of a thin $4 \mathrm{H}-\mathrm{SiC}$ epitaxial layer at the growth time of $30 \mathrm{~min}$. It is thought that the $3 \mathrm{C}$-inclusion density increased with an increase in the growth time because there was constant graphite contamination during the epitaxial growth. To investigate the stability of spiral growth, we observed the morphology of spiral hillocks using AFM. Figure 11a,b show AFM images of the spiral hillocks on the $4 \mathrm{H}-\mathrm{SiC}$ epitaxial layers grown for $30 \mathrm{~min}$ and $5 \mathrm{~h}$, respectively. Both spiral hillocks have a terrace width of approximately $250 \mathrm{~nm}$ and a step height of $0.5 \mathrm{~nm}$. The tilt angles of these spiral hillocks were calculated as approximately $0.1^{\circ}$. This suggests that the morphology of the spiral hillocks remained constant when the growth time increased, and stable spiral growth was achieved.
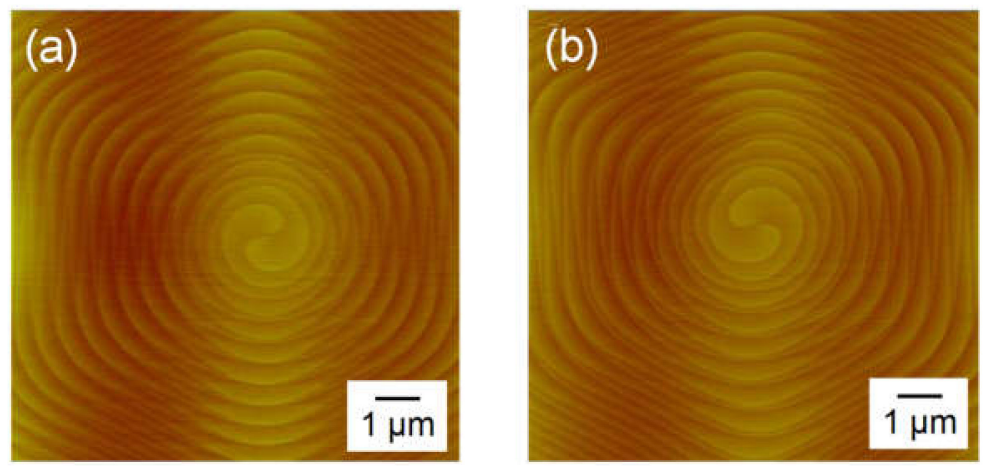

Figure 11. Atomic force microscopy (AFM) images of the spiral hillocks on the on-axis $4 \mathrm{H}-\mathrm{SiC}$ epitaxial layers grown for (a) $30 \mathrm{~min}$ and (b) $5 \mathrm{~h}$ at the growth rate and ramp-up time of $40 \mu \mathrm{m} / \mathrm{h}$ and $60 \mathrm{~min}$, respectively.

Finally, we fabricated a free-standing $4 \mathrm{H}-\mathrm{SiC}$ epitaxial layer. The thick $4 \mathrm{H}-\mathrm{SiC}$ homoepitaxial layer grown on the 3-inch substrate with a ramp-up time of $60 \mathrm{~min}$ and with the thickness of $194 \mu \mathrm{m}$ was separated from the substrate using the KABRA process. Figure 12 shows a photograph of the 3-inch free-standing $4 \mathrm{H}-\mathrm{SiC}$ epitaxial layer. The epitaxial layer is transparent because of low nitrogen doping, and the yellow areas indicate 3C-inclusions. The C-face and Si-face were polished by chemical-mechanical polishing and mirror-polishing, respectively. The thickness of the free-standing $4 \mathrm{H}-\mathrm{SiC}$ epitaxial layer was $182 \mu \mathrm{m}$, which could be handled using tweezers, as shown in Figure 12. Thus, we succeeded in fabricating a 3-inch on-axis $4 \mathrm{H}-\mathrm{SiC}$ free-standing epitaxial layer with a 3C-inclusion density of $2.0 \mathrm{~cm}^{-2}$.

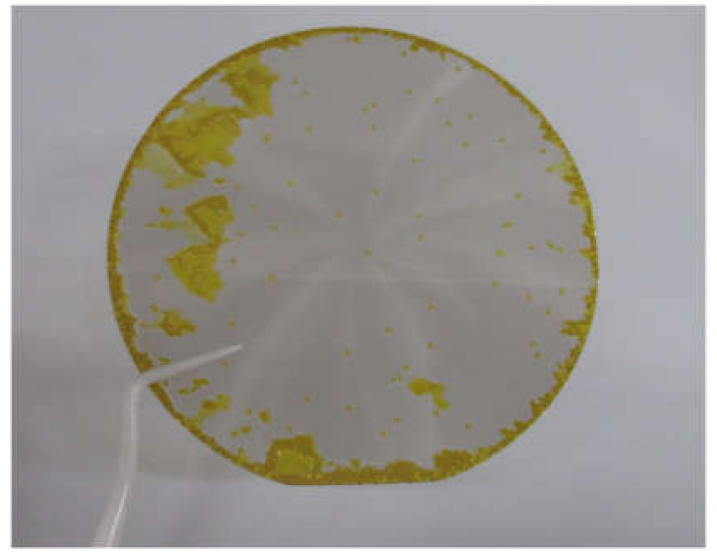

Figure 12. Photograph of the 3-inch on-axis $4 \mathrm{H}-\mathrm{SiC}$ free-standing epitaxial layer. 


\section{Conclusions}

We investigated factors influencing the generation of the 3C-inclusions in $4 \mathrm{H}-\mathrm{SiC} \mathrm{C}$-face on-axis epitaxial layers. We found that the addition of $\mathrm{HCl}$ had no effect on the 3C-inclusion density and the 3C-inclusion was suppressed by increasing the ramp-up time. The 3C-inclusion density of the $4 \mathrm{H}-\mathrm{SiC}$ epitaxial layer decreased to $0.2 \mathrm{~cm}^{-2}$ when increasing the ramp-up time to $60 \mathrm{~min}$ (when the growth rate and growth time were $40 \mu \mathrm{m} / \mathrm{h}$ and $30 \mathrm{~min}$, respectively). It is thought that the $3 \mathrm{C}-\mathrm{SiC}$ nucleation on large terraces of the on-axis substrates-occurring before the substrates were covered with spiral hillocks-was suppressed. Moreover, we investigated other causes for 3C-inclusions and found that there was a high concentration of $C$ near the origin of the $3 C$-inclusion. This indicates that graphite contamination from uncoated graphite products was a cause for the presence of 3C-inclusions. Finally, we succeeded in growing a thick homoepitaxial layer on the 3-inch substrate and demonstrating a free-standing epitaxial layer with a thickness of $182 \mu \mathrm{m}$ and a 3C-inclusion density of $2.0 \mathrm{~cm}^{-2}$.

Author Contributions: Conceptualization, data curation, investigation, formal analysis, writing—original draft preparation, K.M.; supervision, writing-review, K.K.; supervision, H.Y. All authors have read and agreed to the published version of the manuscript.

Funding: This work was supported by JSPS KAKENHI Grant Number JP18K04252, and by the Ebara Hatakeyama Memorial Foundation.

Acknowledgments: The authors would like to thank DISCO Corporation for their support in implementing by the KABRA process.

Conflicts of Interest: The authors declare no conflict of interest.

\section{References}

1. Millan, J.; Godignon, X.; Perpina, X.; Pérez-Tomás, A.; Rebollo, J. A survey of wide bandgap power semiconductor devices. IEEE Trans. Power Electron. 2014, 29, 2155-2163. [CrossRef]

2. Kimoto, T.; Itoh, A.; Matsunami, H. Step-controlled epitaxial growth of high-quality SiC layers. Phys. Status Solidi B 1997, 202, 247-262. [CrossRef]

3. Mercier, F.; Nishizawa, S. Role of surface effects on silicon carbide polytype stability. J. Cryst. Growth 2012, 360, 189-192. [CrossRef]

4. Yonezawa, Y.; Mizushima, T.; Takenaka, K.; Fujisawa, H.; Deguchi, T.; Kato, T.; Harada, S.; Tanaka, Y.; Okamoto, D.; Sometani, M.; et al. Device performance and switching characteristics of $16 \mathrm{kV}$ ultrahigh-voltage SiC flip-type n-channel IE-IGBTs. Mater. Sci. Forum 2015, 821-823, 842-846. [CrossRef]

5. Kimoto, T.; Yonezawa, Y. Current status and perspectives of ultrahigh-voltage SiC power devices. Mater. Sci. Semicond. Process. 2018, 78, 43-56. [CrossRef]

6. Okamoto, M.; Tanaka, M.; Yatsuo, T.; Fukuda, K. Effect of the oxidation process on the electrical characteristics of $4 \mathrm{H}-\mathrm{SiC}$ p-channel metal-oxide-semiconductor field-effect transistors. Appl. Phys. Lett. 2006, 89, 023502. [CrossRef]

7. Kimoto, T.; Danno, K.; Suda, J. Lifetime-killing defects in 4H-SiC epilayers and lifetime control by low-energy electron irradiation. Phys. Status Solidi B 2008, 245, 1327-1336. [CrossRef]

8. Hayashi, T.; Asano, K.; Suda, J.; Kimoto, T. Enhancement and control of carrier lifetimes in p-type 4H-SiC epilayers. J. Appl. Phys. 2012, 112, 064503. [CrossRef]

9. Eto, K.; Suo, H.; Kato, T.; Okumura, H. Growth of p-type $4 \mathrm{H}-\mathrm{SiC}$ single crystals by physical vapor transport using aluminum and nitrogen co-doping. J. Cryst. Growth 2017, 470, 154-158. [CrossRef]

10. Kimoto, T.; Matsunami, H. Surface kinetics of adatoms in vapor phase epitaxial growth of $\operatorname{SiC}$ on $6 \mathrm{H}-\mathrm{SiC}\{0001\}$ vicinal surfaces. J. Appl. Phys. 1994, 75, 850-859. [CrossRef]

11. Jacobson, H.; Birch, J.; Yakimova, R.; Syväjärvi, M.; Bergman, J.P.; Ellison, A.; Tuomi, T.; Janzén, E. Dislocation evolution in 4H-SiC epitaxial layers. J. Appl. Phys. 2002, 91, 6354-6360. [CrossRef]

12. Miyasaka, A.; Kojima, K.; Momose, K.; Osawa, H.; Okumura, H. Improvement of quality of thick $4 \mathrm{H}-\mathrm{SiC}$ epilayers. Mater. Sci. Forum 2017, 897, 59-62. [CrossRef] 
13. Thierry, J.N.; Hassan, J.; Lazar, M.; Planson, D.; Bano, E.; Henry, A.; Janzén, E.; Brosselard, P. Observation of the generation of stacking faults and active degradation measurements on off-axis and on-axis $4 \mathrm{H}-\mathrm{SiC} \mathrm{PiN}$ diodes. Appl. Phys. Lett. 2012, 101, 222111. [CrossRef]

14. Masumoto, K.; Kojima, K.; Okumura, H. Study of spiral growth on $4 \mathrm{H}$-silicon carbide on-axis substrates. J. Cryst. Growth 2017, 475, 251-255. [CrossRef]

15. Leone, S.; Pedersen, H.; Henry, A.; Kordina, O.; Janzén, E. Thick homoepitaxial layers grown on on-axis Si-face $6 \mathrm{H}$ - and $4 \mathrm{H}-\mathrm{SiC}$ substrates with $\mathrm{HCl}$ addition. J. Cryst. Growth 2009, 312, 24-32. [CrossRef]

16. Leone, S.; Pedersen, H.; Henry, A.; Kordina, O.; Janzén, E. Homoepitaxial growth of 4H-SiC on on-axis Si-face substrates using chloride-based CVD. Mater. Sci. Forum 2009, 600-603, 107-110. [CrossRef]

17. Leone, S.; Henry, A.; Kordina, O.; Janzén, E. Chloride-based CVD at high growth rates on 3" vicinal off-angles SiC wafers. Mater. Sci. Forum 2010, 645-648, 107-110. [CrossRef]

18. Knippenberg, W.F. Growth phenomena in silicon carbide. Philips Res. Rep. 1963, 18, 161-274.

19. Hassan, J.; Karhu, R.; Lilja, L.; Janzén, E. Wafer scale on-axis homoepitaxial growth of $4 \mathrm{H}-\mathrm{SiC}(0001)$ for high-power devices: Influence of different gas phase chemistries and growth rate limitations. Cryst. Growth Des. 2019, 19, 3288-3297. [CrossRef]

20. Leone, S.; Beyer, F.C.; Pedersen, H.; Kordina, O.; Henry, A.; Janzén, E. High growth rate of 4H-SiC epilayers on on-axis substrates with different chlorinated precursors. Cryst. Growth Des. 2010, 10, 5334-5340. [CrossRef]

21. Kojima, K.; Okumura, H.; Kuroda, S.; Arai, K. Homoepitaxial growth of $4 \mathrm{H}-\mathrm{SiC}$ on on-axis (000-1) C-face substrates by chemical vapor deposition. J. Cryst. Growth 2004, 269, 367-376. [CrossRef]

22. The New Generation of SiC Wafer Production High-Speed Ingot Slicing with a Greatly Increased Number of Wafers Produced KABRA Process Debut. Available online: https://www.disco.co.jp/kabra/index_eg.html (accessed on 28 October 2020).

23. Hirata, K. New laser slicing technology named KABRA process enables high speed and high efficiency $\mathrm{SiC}$ slicing. In Proceedings of the Laser-Based Micro- and Nanoprocessing XII, San Francisco, CA, USA, 27 January-1 February 2018; Klotzbach, U., Washio, K., Kling, R., Eds.; SPIE Press: Bellingham, WA, USA, 2018; p. 1052003.

24. Ishida, Y.; Takahashi, T.; Okumura, H.; Arai, K.; Yoshida, S. Development of a practical high-rate CVD system. Mater. Sci. Forum 2009, 600-603, 119-122. [CrossRef]

25. Technical Committee on Semiconductor Reliability. Technical Report of Japan Electronics and Information Technology Industries Association: JEITA EDR-4712/100 Non-Destructive Recognition Procedures of Defects in Silicon Carbide Wafers (Part 1: Classification of Defects); Japan Electronics and Information Technology Industries Association: Tokyo, Japan, 2016.

26. Masumoto, K.; Tamura, K.; Kudou, C.; Nishio, J.; Ito, S.; Kojima, K.; Ohno, T.; Okumura, H. Suppression of short step bunching generated on $4 \mathrm{H}-\mathrm{SiC}$ Si-face substrates with vicinal off-angle. J. Cryst. Growth 2014, 401, 673-676. [CrossRef]

Publisher's Note: MDPI stays neutral with regard to jurisdictional claims in published maps and institutional affiliations.

(C) 2020 by the authors. Licensee MDPI, Basel, Switzerland. This article is an open access article distributed under the terms and conditions of the Creative Commons Attribution (CC BY) license (http://creativecommons.org/licenses/by/4.0/). 